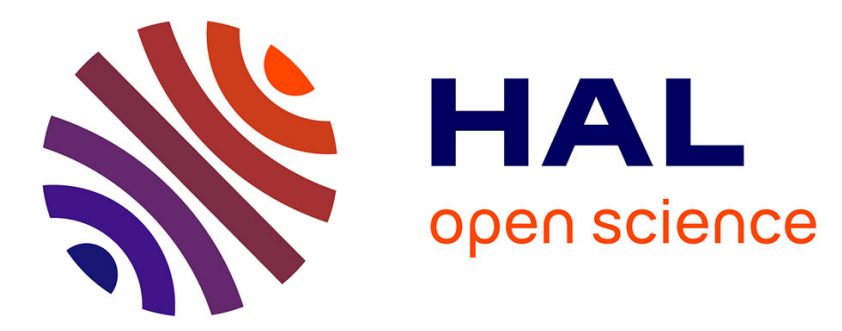

\title{
FAN DESIGN INVESTIGATION ON THE AIRBUS NAUTILIUS ENGINE INTEGRATION CONCEPT
}

Benjamin Godard, Camil Negulescu

\section{To cite this version:}

Benjamin Godard, Camil Negulescu. FAN DESIGN INVESTIGATION ON THE AIRBUS NAUTILIUS ENGINE INTEGRATION CONCEPT. ASME Turbo Expo 2020, Sep 2020, Virtual, Online, United Kingdom. hal-03045952

\section{HAL Id: hal-03045952 https://hal.science/hal-03045952}

Submitted on 8 Dec 2020

HAL is a multi-disciplinary open access archive for the deposit and dissemination of scientific research documents, whether they are published or not. The documents may come from teaching and research institutions in France or abroad, or from public or private research centers.
L'archive ouverte pluridisciplinaire HAL, est destinée au dépôt et à la diffusion de documents scientifiques de niveau recherche, publiés ou non, émanant des établissements d'enseignement et de recherche français ou étrangers, des laboratoires publics ou privés. 
September 21-25, 2020, Virtual, Online

\section{FAN DESIGN INVESTIGATION ON THE AIRBUS NAUTILIUS ENGINE INTEGRATION CONCEPT}

\author{
Benjamin Godard \\ Onera - The French Aerospace Lab \\ Meudon, France \\ benjamin.godard@onera.fr
}

\author{
Camil Negulescu \\ Airbus Operations SAS \\ Toulouse, France \\ camil.negulescu@airbus.com
}

\section{ABSTRACT}

Recent innovative engine integration systems present interesting prospects for considerable aircraft fuel burn reduction. In this context, the Airbus Nautilius is a patented engine integration concept embedding two Ultra High Bypass Ratio (UHBR) turbofans at the rear of the fuselage so as to take the full benefit of the boundary layer ingestion (BLI). This concept presents very promising power savings compared to classical podded configurations when neglecting the penalty on fan performance. However, as the engine is now working in distorted boundary layer flow conditions, these benefits can be partially offset by an additional fan performance penalty. In order to assess these additional losses and therefore to refine the potential of this concept, a numerical fan design activity has been conducted by Onera on behalf of and in collaboration with Airbus. First, blade design modifications have been applied to a pre-existing UHBR fan stage originally designed for "classical" podded configurations in order to maximize the isentropic efficiency in cruise conditions. The results of this first activity shows that more than half of the fan isentropic efficiency penalty due to the distortion at the engine inlet can be recovered by few design iterations. Secondly, an operability assessment at take-off high-lift conditions has been conducted on the optimized geometry and ensures that the fan stall margin remains acceptable. In conclusion, these results confirm the initial potential and mark an additional step towards a broader assessment of the Nautilius engine integration concept, which shall be further completed by acoustic and aeroelastic studies.

\section{NOMENCLATURE}

BLI Boundary Layer Ingestion

OGV Outlet Guide Vane

PSC Power Saving Coefficient [\%]

UHBR Ultra High Bypass Ratio

$a_{s} \quad$ Sound velocity $[\mathrm{m} / \mathrm{s}]$

$C_{L} \quad$ Lift Coefficient [-]

$c \quad$ Blade chord length $[m]$

$F_{x} \quad$ Axial net force $[N]$

$F_{x_{R_{x}=0}} \quad$ Axial net force at thrust-drag equilibrium $[N]$

$H \quad$ Blade to blade staggered spacing $[\mathrm{m}]$

$h \quad$ Relative height $[-]$

$M \quad$ Absolute Mach number [-]

$M_{\text {rel }} \quad$ Relative Mach number [-]

$M_{x} \quad$ Axial Mach number [-]

$\dot{m} \quad$ Massflow rate $[\mathrm{kg} / \mathrm{s}]$

$\dot{m}_{\text {corr }} \quad$ Corrected massflow rate $[\mathrm{kg} / \mathrm{s}]$

$\overline{\dot{m}_{\text {corr }}}$

$\dot{m}_{\text {corr norm }}$

Normalized corrected massflow rate $[-]$

Normalization value for corrected massflow rate $[\mathrm{kg} / \mathrm{s}]$

$\dot{m}_{r e f} \quad$ Reference Massflow rate $[\mathrm{kg} / \mathrm{s}]$

$p \quad$ Static pressure $[\mathrm{Pa}]$

$p_{i} \quad$ Stagnation pressure $[\mathrm{Pa}]$

$p_{i, 0} \quad$ Far field stagnation pressure $[\mathrm{Pa}]$

$p_{\text {piv }} \quad$ Pivot static pressure $[\mathrm{Pa}]$

$S M \quad$ Stability margin [\%]

$T$

$T_{i} \quad$ Stagnation temperature $[K]$ 


$\begin{array}{ll}T_{i}, 0 & \text { Far field stagnation temperature }[\mathrm{K}] \\ \vec{v} & \text { Absolute flow velocity }[\mathrm{m} / \mathrm{s}] \\ \vec{w} & \text { Relative flow velocity }[\mathrm{m} / \mathrm{s}] \\ U_{t i p} & \text { Fan tip rotating speed }[\mathrm{m} / \mathrm{s}] \\ (x, y, z) & \text { Cartesian coordinates } \\ (x, r, \theta) & \text { Cylindrical coordinates } \\ \alpha & \left.\text { Absolute flow angle [ }{ }^{\circ}\right] \\ \beta & \text { Relative flow angle }\left[^{\circ}\right] \\ \lambda_{4} & \text { Valve factor }[\mathrm{Pa}] \\ \eta_{i s} & \text { Isentropic efficiency }[-] \\ \rho & \text { Density }\left[\mathrm{kg} / \mathrm{m}^{3}\right] \\ \Omega & \text { Rotating speed }[\mathrm{rad} / \mathrm{s}]\end{array}$

\section{CONTEXT AND OBJECTIVES}

As a response to the increase demand of air-traffic and based on the Climate Change meeting held in Paris in 2015 (COP 21), the Advisory Council for Aviation Research and Innovation in Europe (ACARE) [1] recommends emission reduction up to $75 \%$ in terms of $\mathrm{CO}_{2}$ and $90 \%$ in terms of NOx and $65 \%$ of noise reduction by 2050 . Although the tube-and-wing design used over the last 70 years has been strongly improved from its initial performance, improvements are slowing down, which illustrates that the potential for improvement tends towards its limit [2]. Therefore, in order to reach the ambitious COP 21 objectives, innovation must come with a change of aircraft architecture paradigm.

Among the variety of innovative technologies that have risen to address this issue (UHBR, distributed propulsion, electric/hybrid powered engines, etc.) Boundary Layer Ingesting (BLI) systems have sparked the interest of many as they show estimated power savings from $3 \%$ to $12 \%$ depending on the considered configuration $[3,4,5,6,7,8]$. Basically, the concept consists in embedding the nacelle within the airframe so as to ingest the boundary layer of the fuselage. As a result, the engine inlet and outlet velocities are reduced which leads to an increase of the propulsive efficiency. The success of such technology relies on the abilities:

(i) to ingest a maximum amount of boundary layer and

(ii) to design a fan capable of operating in distorted conditions.

Regarding the first issue (i), several strategies try to exploit the BLI. For example, the MIT D8 is a large fuselage aircraft concept (double-bubble) with two to three embedded rear-mounted engines that ingest the upper-face boundary layer of the fuselage [9]. The estimated (through a power-balance method [10]) power saving reaches $8 \%$ compared to the same aircraft with podded engines. A similar large fuselage aircraft configuration which benefits from the ingestion of a part of the fuselage boundary layer is the Onera NOVA configuration and demonstrates a $5 \%$ gain in power saving compared to a "classical" wing-podded engine integration [11]. These last concepts have the particularity to only partially ingest the fuselage boundary layer $(\approx 30$ -
$50 \%$ ) and in a non-uniform way with respect to the engine fan. In order to limit the fan distortion and to increase the amount of ingested boundary layer, some configurations integrate the engines in a axisymmetrical manner (i.e. $360^{\circ}$ ) around the rear end of the fuselage. This is the case of the NASA STARC-ABL, which is a conventional single aisle tube-and-wing aircraft with two classical under-wing propulsors and an additional electrically powered fan at the rear with its hub merged with the aircraft tail [12]. However, in this configuration, only one engine make use of the boundary layer ingestion while the other two ingest a clean airflow. The idea of the Nautilius engine integration concept is to maximize the quantity of the ingested boundary layer through the contribution of the whole propulsive system. This is achieved by astutely integrating two engines at the rear of the fuselage where the tail has been split in two parts. Thus, these parts also serve as hubs for both engines. FIGURE 1 presents a caption of the
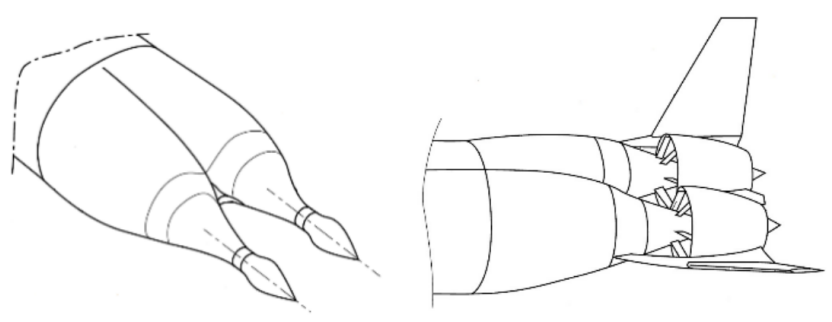

FIGURE 1. Nautilius Engine Integration Concept [13]

Nautilius engine integration concept extracted from [13], while FIGURE 2 presents its application on the Onera NOVA aircraft (left picture). A "podded" version is also presented in FIGURE 2 (right picture) and is used in this study as reference for power saving estimations. In order to assess these configurations, a first study has been conducted in [14] by means of steady CFD computations with the fan stage modeled by an actuator disc. As the actuator disc approach can be less robust and less representative than more recent fan modeling methods $[15,16,17,18,19]$, power saving estimations could be refined by using body-force modeling methods [20].

Even though BLI concepts show interesting power-savings, it is important to account for the fan performance in order to consolidate these estimations as well as to ensure the operability and acceptable noise levels and aeromechanical response [21,22,23]. However, designing a fan in BLI conditions is a real challenge. Nevertheless, several authors have already managed to draw some guidelines using both low-fidelity methods [24,25] or more advanced unsteady approaches. In particular, fan design in BLI conditions must account for non-axisymetric inflows, which can be partially addressed by non-axisymetric components (ex. OGV, channel, etc.) [26,27]. Besides, maintaining an acceptable 


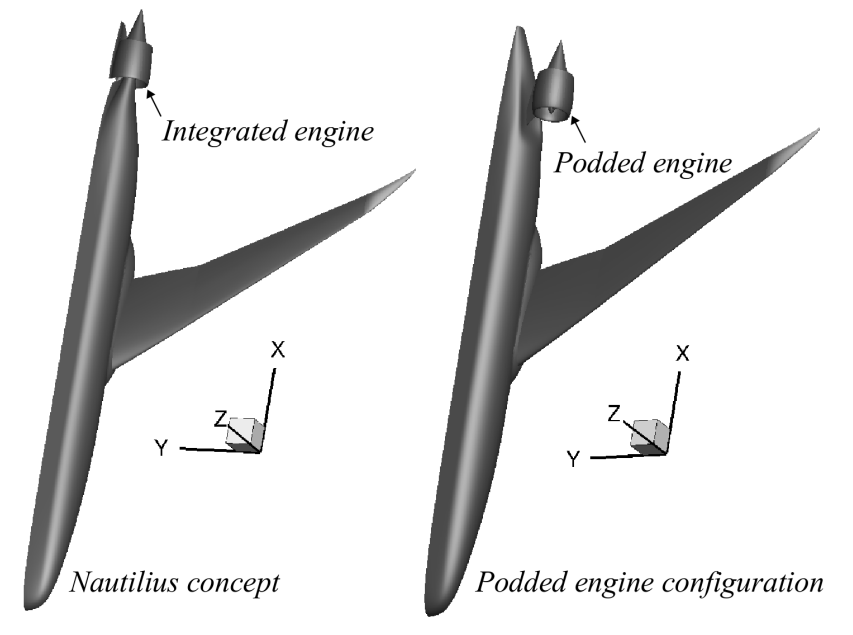

FIGURE 2. Nautilius Engine Integration Concept (left) and Reference Podded Engine Configuration (right) applied on the NOVA configuration

fan stage operability in distorted flow conditions is also a challenging issue and has been addressed by several authors [28]. Local flow heterogeneities can indeed induce stall, although it might not always settle throughout the whole circumference [29].

In order to pursue the Nautilius concept assessment, the objectives of this study are therefore:

(i) to confirm the BLI power saving estimations by using the body-force modeling method in aircraft simulations,

(ii) to design a fan stage that maximizes the isentropic efficiency in cruise conditions using the inlet cartography from the aircraft/body-force computation and

(iii) to assess the operability of the design in take-off high-lift conditions.

This paper presents in a first part the numerical set-up for both aircraft and fan stage computations. Then, the abovepresented aspects are addressed through three different sections, i.e. aircraft computations, fan stage design and operability assessment.

\section{TEST-CASE AND NUMERICAL SET-UP}

The Nautilius engine integration as well as the reference podded concept have been applied on the NOVA airplane as illustrated in FIGURE 2. The initial propulsor for both configurations is an in-house fan stage whose characteristics are described in TABLE 1. CFD simulations are performed with the elsA solver developed by ONERA on structured meshes [30]. Steady simulations are run with an implicit pseudo-time marching method with backward Euler scheme. Two types of computations have been run for this study. The first one refers to steady-RANS computa-
TABLE 1. Fan Stage Characteristics

\begin{tabular}{cc}
\hline \hline Number of fan/OGV blades [-] & $18 / 40$ \\
\hline Nominal pressure ratio [-] & 1.35 \\
\hline Tip relative Mach number [-] & $<1.2$ \\
\hline Flow coefficient $\phi=\overline{v_{x}} / U_{t i p}[-]$ & 0.6 \\
\hline \hline
\end{tabular}

tions of the aircraft where the fan stage is modeled using bodyforce source terms. These computations are used to estimate the power saving of the configuration without taking into account fan performance. They also serve to define the inlet boundary conditions for unsteady-RANS simulations of the isolated fan stage as a second set of computations. This process enables to considerably speed up aircraft design iterations as computing both the aircraft and the fan stage would imply a mesh size ten times biger and the use of an unsteady approach. The implied assumptions here are that the resulting distortion is supposed close enough to what would have been obtained with a coupled aircraft/meshedrotor URANS computation and that it remains steady throughout a blade rotation $[31,20]$.

Regarding the aircraft computations, equations are discretized in space using a second order Jameson spatial scheme [32] while the Spalart-Allmaras model [33] ensures turbulence closure. The different parts (i.e. the fuselage, the wings, and the nacelle) are assembled together within a cartesian grid by means of the chimera technique. Figure 3 presents a caption of the com-

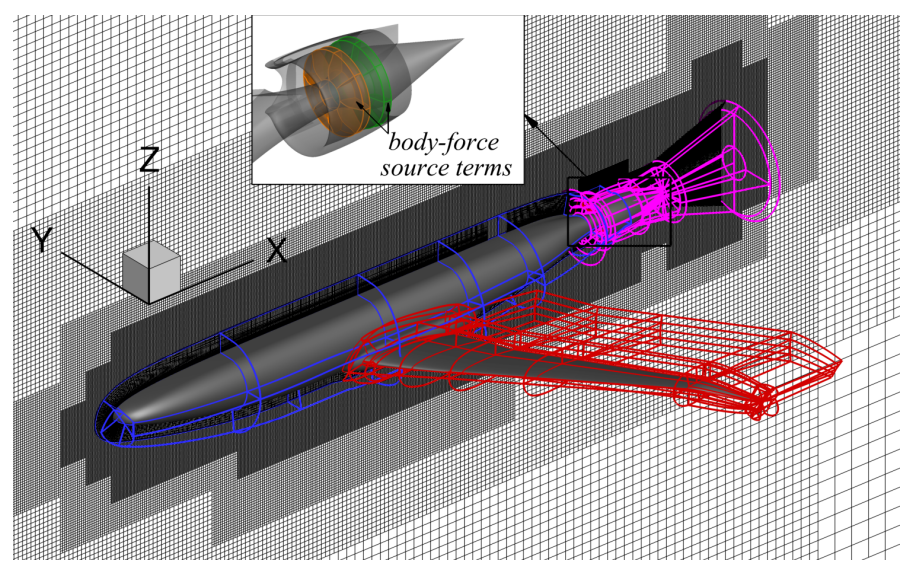

FIGURE 3. Aircraft computational domain (Nautilius engine integration case)

putational domain for the Nautilius configuration. This domain mesh-size counts approximately $9.5 \times 10^{6}$ elements. Besides, a far field condition is applied at the domain borders in order to 
ensure the flight Mach number $\left(M_{\text {flight }}=0.82\right.$ at cruise $)$ as well as the far field stagnation values $p_{i, 0}$ (pressure) and $T_{i, 0}$ (temperature). Finally, a body-force formulation is used to model the fan stage and is based on the work of [24] where only a force component $f_{n}$ perpendicular (in the flow plane ${ }^{1}$ ) to the flow relative velocity $\vec{w}$ is considered :

$$
f_{n}=\frac{w^{2}}{H} \pi \delta
$$

in which:

(i) $H$ is the blade-to-blade staggered spacing and

(ii) $\delta=\arcsin \left(\frac{\vec{w} \cdot \vec{n}_{s}}{\|\vec{w}\|}\right)$ is the local deviation in the plane defined by the blade profile normal $\vec{n}_{s}$.

Regarding fan stage (U)RANS computations, equations are discretized in space using a cell-centered finite volume method with the second order upwind scheme of Roe [34]. The $k-l$ model of Smith [35] ensures turbulence closure. The grid was generated using NUMECA AUTOGRID ${ }^{T M}$ software [36] with a domain mesh size of approximately $80 \times 10^{6}$ elements (cf. FIGURE 4 for illustrations). The outlet boundary conditions are set
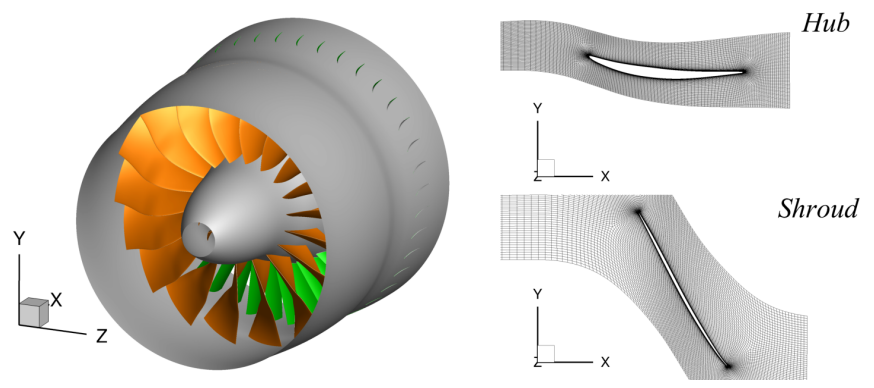

FIGURE 4. Fan stage computational domain (left) and mesh circumferential slices of the fan (right)

with a radial equilibrium defined by a pivot static pressure $p_{p i v}$ located at the hub. Iso-rotating speed characteristics are obtained by adjusting the pivot static pressure through a valve factor $\lambda_{4}$ :

$$
p_{p i v, n+1}=p_{r e f}+\lambda_{4}\left(\frac{\dot{m}_{n}}{\dot{m}_{r e f}}\right)^{2}
$$

where $\dot{m}_{n}$ is the massflow rate at iteration $n$ and $\dot{m}_{r e f}$ and $p_{r e f}$ are massflow rate and static pressure values of reference.

\footnotetext{
${ }^{1}$ The flow plane is defined by a normal $\vec{n}_{p}$ such as $\vec{f} \cdot \vec{n}_{p}=0$
}

\section{AIRFRAME COMPUTATIONS}

Computations have been run in cruise conditions on the NOVA-airframe geometry with the engine being integrated based on the Nautilius concept or integrated on structural arms (cf. FIGURE 2). Several differences arise between the two configurations. First, global aero-propulsive performances have been assessed and compared by means of an exergy analysis [37]. Among the variety of conclusions that can arise from such power breakdown analysis, the fan power can be plotted against the corrected axial net force variation defined by equation (3):

$$
\text { Corrected Axial Net Force Variation }=\frac{F_{x}-F_{x_{R x=0}}}{F_{x_{R x}=0}} \times 100
$$

in which is the axial net force $F_{x}$ is corrected by a reference value $F_{x_{R_{x}=0}}$ corresponding to balanced thrust-drag zero net force $\left(R_{x}=0\right)$ equilibrium conditions. As both configurations have been evaluated at iso-aircraft angle of attack, while a iso- $C_{L}$ comparison would have been fairer, an induced drag correction term has been introduced in the reference value $F_{x_{R x}=0}$ of the Nautilius configuration. FIGURE 5 presents the fan power evolution

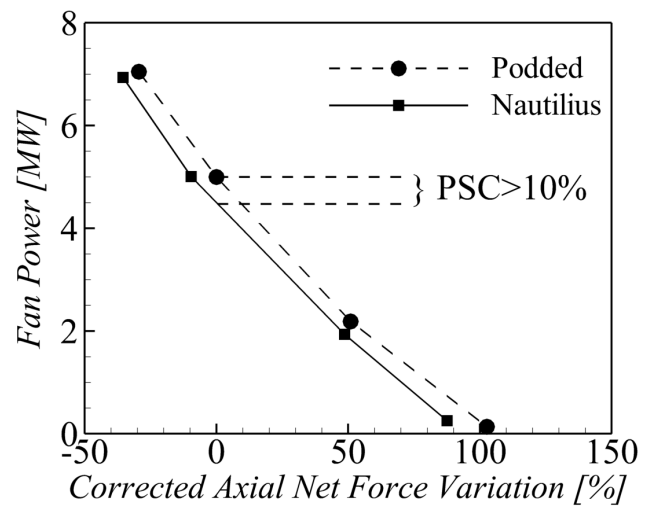

FIGURE 5. Comparisons of Fan Power vs. Corrected Axial Net Force Variation for the Nautilius and the Podded Configurations for Several Rotating Speeds (Induced Drag Correction Included) $\left(M_{\text {flight }}=\right.$ 0.82$, Alt. $=37,000 f t)$ )

against the corrected axial net force variation for several rotating speeds. Results show that the Nautilius configuration requires less fan power. It notably presents a power saving coefficient (PSC) superior to $10 \%$ at thrust-drag equilibrium ${ }^{2}$.

\footnotetext{
${ }^{2}$ It has to be also noted that two elements have been omitted for simplification in the performed computations, the tails as well as the core jet. These two elements balance each other in terms of drag and thrust. The fan power required at the $0 \%$ corrected axial net force variation equilibrium point of the simulation represents therefore quite well the fan power required for the whole aircraft.
} 
Although favored by the performance analysis, the Nautilius configuration presents strong airflow heterogeneities compared to the podded engine configuration. In particular, the Nautilius integration induces a strong inlet distortion (a 28\% local loss can be reached in terms of stagnation pressure) in both the radial and the circumferential directions (cf. FIGURE 6). This additional
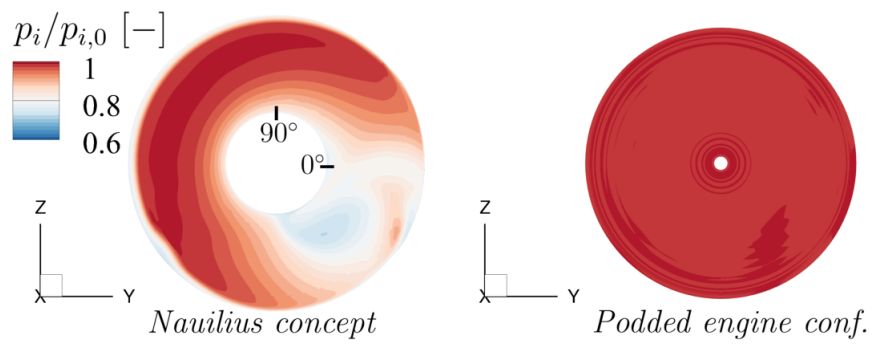

FIGURE 6. Inlet Distortions Colored by the Stagnation Pressure Ratio of the Nautilius (left) and the Reference Podded Engine (right) Configurations (Steady RANS Computations with Body-force Source Terms)

inlet distortion is caused by the way the boundary layer is ingested. Indeed, FIGURE 7 presents $\mathrm{Y}$ and $\mathrm{Z}$ slices colored by

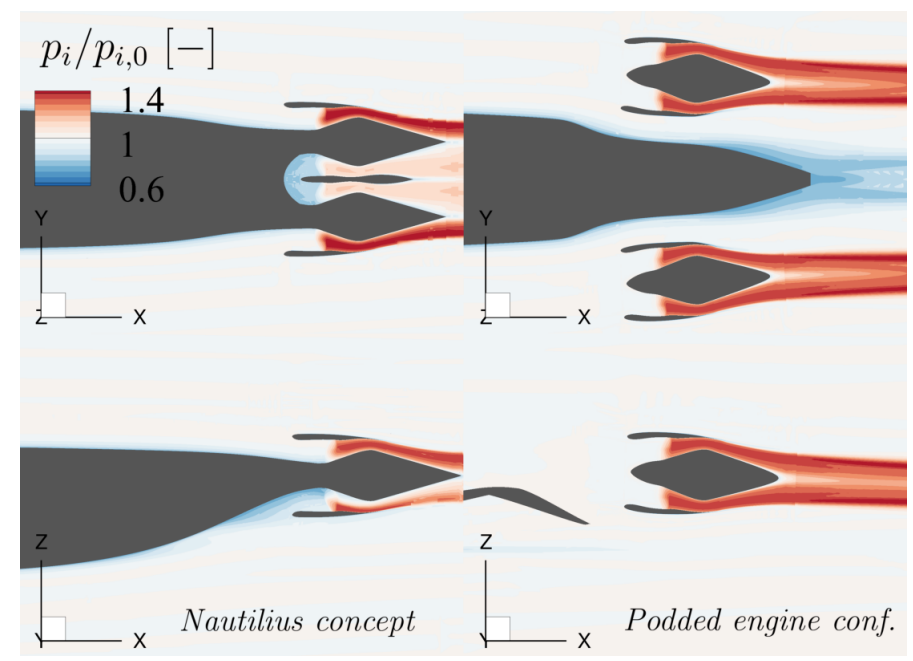

FIGURE 7. Y (down) and Z (up) Slices Colored by the Stagnation Pressure Ratio of the Nautilius (left) and the Reference Podded Engine (right) Configurations (Steady RANS Computations with Body-force Source Terms)

the stagnation pressure ratio $p_{i} / p_{i, 0}$ (where $p_{i}$ is the local stag- nation pressure) and thus illustrates the non-axisymmetrical behavior of the boundary layer around the tail. In particular, it can be seen that the boundary layer tends to thicken and to be swept toward the lower-inner surface of the fuselage tail. This behavior is due to the intensified slope below the fuselage tail as well as in the twin tail separation region. As a result of the nacelle local blockage effects and tail pressure gradients, the low-momentum region gathers at the lower-inner corner of the intake (between 4 and 5 o'clock in FIGURE 6 left picture). The stagnation pressure ratio deficit is intensified even more due to the ingestion of a vortex generated by the swirling effect of the rear fuselage slope. FIGURE 8 illustrates the origin of the vortex with a caption of

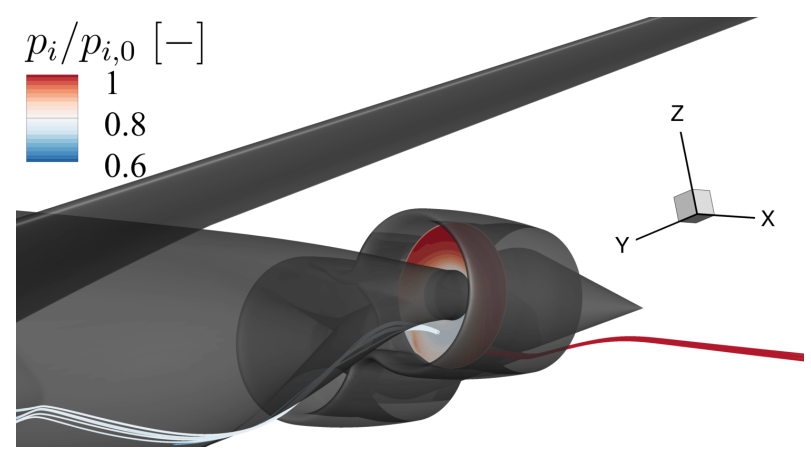

FIGURE 8. Streamlines Colored by Stagnation Pressure Ratio of the Nautilius Configuration (Steady RANS Computations with Body-force Source Terms) $\left(M_{\text {flight }}=0.82\right)$

streamlines colored by the stagnation pressure ratio.

Finally, even though the Nautilius configuration is promising at first glance, the fan inlet distortion brings (a priori) some concerns. While this study has been conducted using the presented inlet distortion, additional airframe design iterations have been realized in parallel and have not only increased the power saving coefficient but also reduced the inlet distortion intensity.

\section{FAN DESIGN ITERATIONS}

For this preliminary fan design activity, only aerodynamic fan design aspects are considered with the objective to maximize fan isentropic efficiency in cruise conditions and to assess the fan operability at take-off high-lift conditions. No structural integrity (including aeroelastic behavior) verifications have been performed. The initial baseline geometry itself has been designed for structural integrity. Therefore, in order to keep as much as possible a realistic design during the process, main structural design criteria such as blade profile centers of gravity, chord lengths and thicknesses are kept constant. Hence, solely the fan and OGV profiles inlet and outlet angles are modified in 
order to adapt the blade profiles to the local flow conditions and thus to improve fan performance.

Two kind of computations have been used in order to conduct the fan design study. First, single blade-channel RANS computations (with a rotor-stator mixing-plane condition) have been performed with the inlet boundary condition set with the circumferential averaged distortions of FIGURE 6. FIGURE 9 left caption presents this averaged stagnation pressure inlet

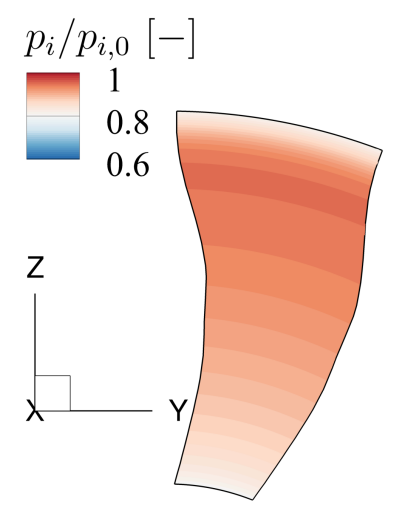

Averaged Inlet Distortion

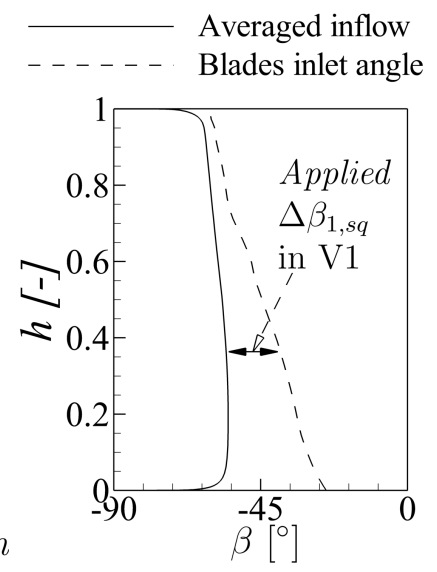

FIGURE 9. Circumferential Averaged Fan Inlet Distortion of the Nautilius Configuration (Left) and Height Distributions of Averaged Relative Angles of the Flow and the Geometry (Right)

boundary condition for the Nautilius configuration. The second kind of computations are whole circumference URANS computations with the distortions of FIGURE 6 directly interpolated at the window of the inlet domain. To some extent, the comparison of these two kinds of computations enables to highlight the effect of the inflow non-axiymmetry on the fan performances. Indeed, with the single blade-channel mixing-plane approach, the nonaxisymmetry is completely erased, which globally eases the fan working conditions. As a result, the isentropic efficiency is overestimated. Yet, the single blade-channel mixing-plane results remain useful in order to assess the effect of the radial distortion. In addition, it enables to quickly estimate the fan performance characteristics and in particular the position of the assessed working condition from the point of maximum efficiency.

Results show that the distortion has a strong impact on fan performances. Indeed, FIGURE 10 shows fan stage performance maps in terms of stagnation pressure ratio $p_{i} / p_{i, 0}$ (upper figure) and isentropic efficiency $\eta_{i s, \text { stage }}$ (lower figure) against the nor-
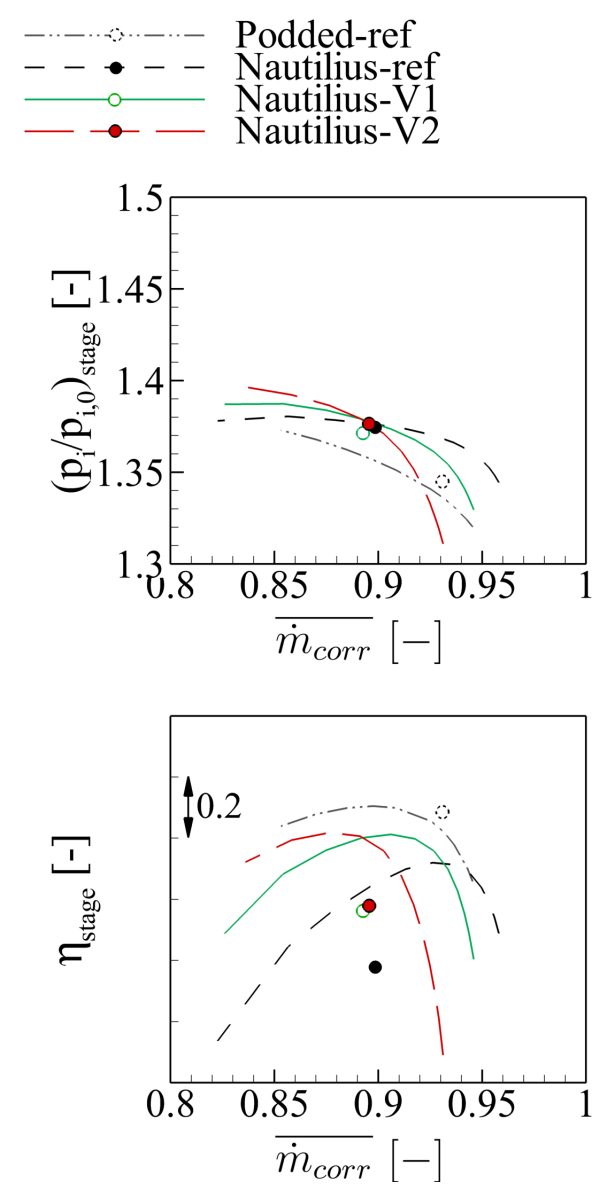

FIGURE 10. Fan stage stagnation Pressure Ratio and Isentropic Efficiency Performance Maps with Iso-speeds RANS/Mixing-plane (Lines) and URANS Evaluations (Dots) at Cruise-Flight Conditions for Different Fan Geometries

malized corrected massflow rate defined by equation (4):

$$
\overline{\dot{m}_{\text {corr }}}=\frac{\dot{m} \frac{\sqrt{T_{i, 0} / T_{i, r e f}}}{p_{i, 0} / p_{i, r e f}}}{\dot{m}_{\text {corr }, \text { norm }}}
$$

where $p_{i, 0}$ and $T_{i, 0}$ are the upstream stagnation pressure and temperature while $p_{i, r e f}=101325 P a$ and $T_{i, r e f}=288.15 \mathrm{~K}$ are standard values at ISA- 0 . Also, $\dot{m}$ is the massflow rate and $\dot{m}_{\text {corr,norm }}$ is a normalization value. In this FIGURE 10, iso-rotating speed lines represent RANS/mixing-plane computations, while results from URANS computations at flight conditions are plotted with dots. In these figures, based on the URANS computations, the reference geometry in BLI conditions demonstrates significant losses of several percent of isentropic efficiency compared to the 
Podded configuration ${ }^{3}$. This last comparison is made at the corresponding cruise condition of each design. It can also be noted a migration of the engine operating point in BLI conditions towards lower massflow rate and higher fan stage stagnation pressure ratio. In order to adapt the fan to the BLI conditions, a first design step referred as "V1" has consisted in pitching the fan blades so as to match the inlet blade profile angle $\left(\beta_{1, s q}\right)$ with the incoming flow angles of the averaged inlet distortion (this procedure similarly affect the outlet blade profile angle $\beta_{2, s q}$ ). Even though this modification does not ensure the fan adaptation throughout the distorted circumference, it still globally improves the performances. This modification is illustrated in FIGURE 9 right caption while results are also plotted in FIGURE 10 (cf. green lines and green dots). This simple geometric modification enables to recover one third of the isentropic efficiency loss. A second design iteration referred as "V2" has then consisted in applying a constant closing of the inlet blade angle of the fan along the span so as to shift the iso-speed characteristics to lower massflow-rate (this time, the procedure does not affect the outlet blade profile angle $\beta_{2, s q}$ and a chord variation has been applied so as to keep a constant camber). The goal of this iteration is to place the cruise working conditions at the right side of the maximum efficiency point or, in other words, to place the working condition further away from the stall margin ${ }^{4}$. This modification has the effect to slightly reduce the isentropic efficiency loss (cf. dashed red lines and red dots in FIGURE 10). This improvement can be attributed to the reduction of a fan blade separation located in the region of intense vorticity and velocity gradients. FIGURE 11 illustrates this effect with slices extracted at $h=40 \%$ colored by the normalized entropy of the different configurations and designs. The blade separation cancellation can be qualitatively observed and appears even more pronounced for the design iteration $\mathrm{V} 2$.

The next iteration has been focused on OGV blades. Similarly as with the fan row, the strategy has consisted in adapting the blade profiles to the incoming flow. However, contrary to the rotating fan, this operation can be performed in a nonaxisymmetric way. Each OGV blade can thus be adapted to its local incoming flow. More precisely, the process has consisted in extracting the local flow angles from the time-averaged flow upstream of the OGV blades and in applying the difference between these flow angles and the OGV blades' inlet angles to the new geometry (refered as "V3"). FIGURE 12 presents the resulting OGV profiles near the hub (where the distortion is the strongest) (blue) compared to the original one (black). All blade modifications have been applied while conserving centers of gravity as

\footnotetext{
${ }^{3}$ Incidentally, the difference of isentropic efficiency estimations coming from RANS/mixing-plane and URANS $/ 360^{\circ}$ shows the importance of unsteady and non-axisymmetrical effects.

${ }^{4}$ Even though by doing so the stall limit itself is affected, which could mitigate the intended purpose.
}

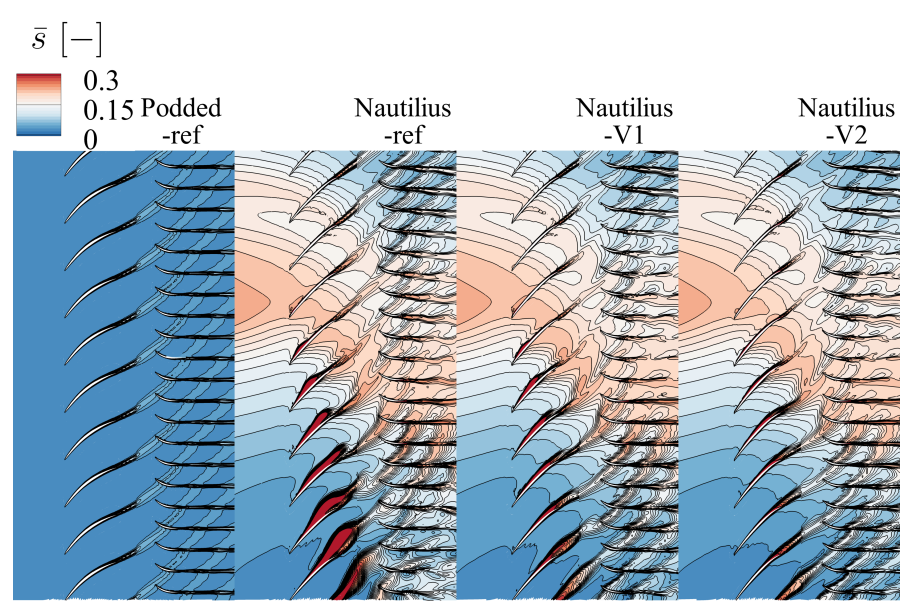

FIGURE 11. Normalized Entropy Slices at $h=40 \%$. Comparisons of the Reference Fan Stage for Podded and Nautilius Configurations and Fan Geometry Iterations V1 and V2

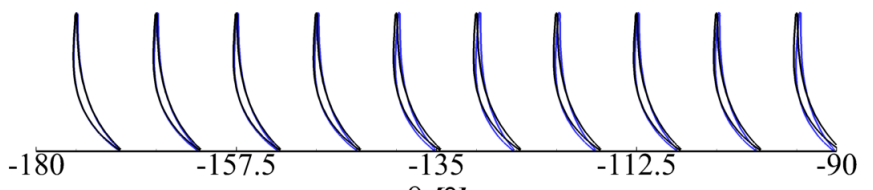

$\theta[\%$

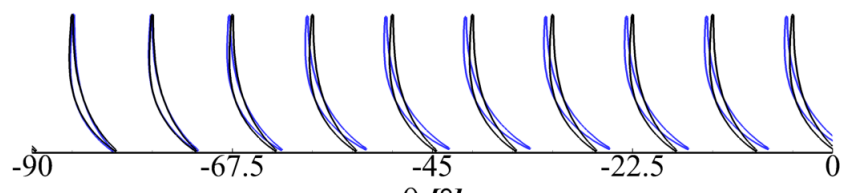

$\theta[\%$
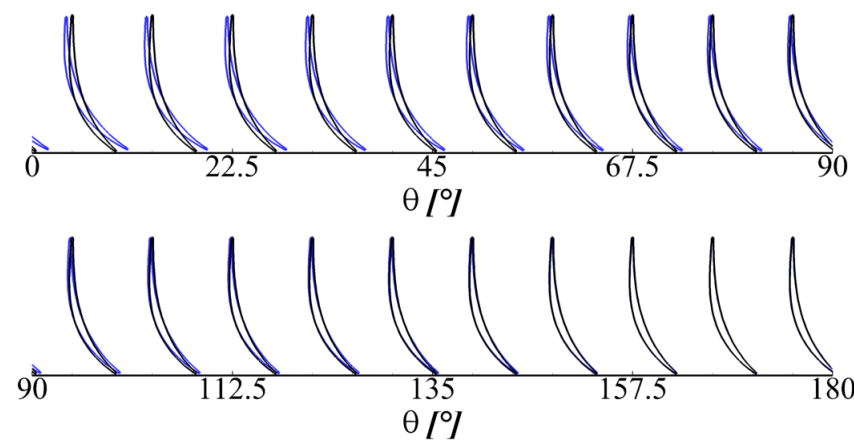

FIGURE 12. OGV Profiles Near the Hub (blue : new geometry, black : reference)

well as conserving the outlet blade profile angles ${ }^{5}$. FIGURE 13 presents the same fan stage performance maps as FIGURE 10 with in addition the results of the new iteration V3. The zoomed square in the right hand side picture highlights the new improve-

\footnotetext{
${ }^{5}$ The objective is indeed to have an axial flow downstream of the OGV
} 


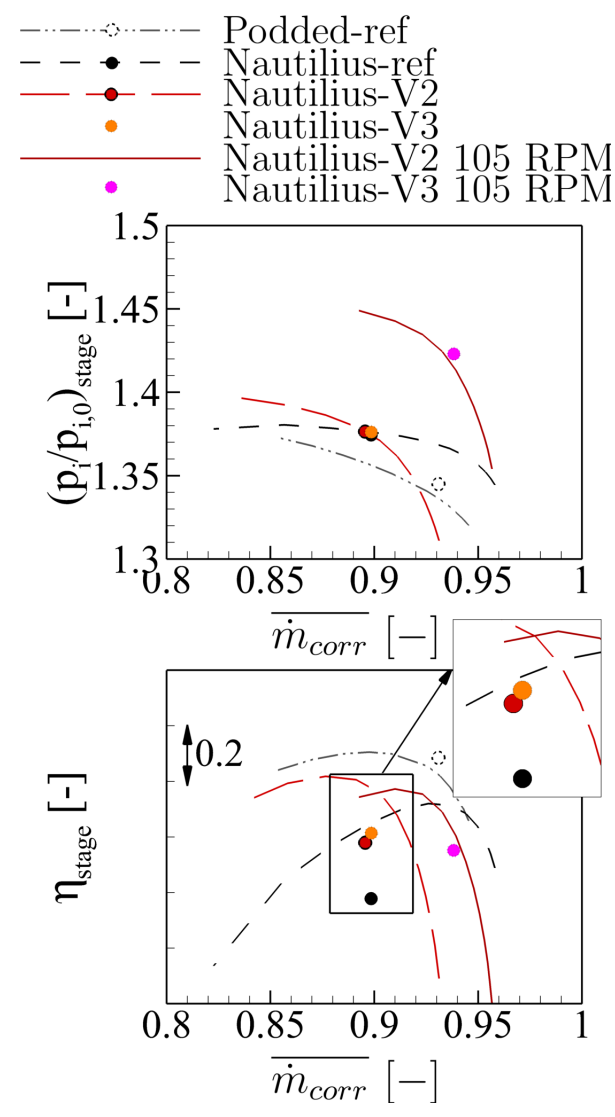

FIGURE 13. Fan stage stagnation Pressure Ratio and Isentropic Efficiency Performance Maps with Iso-speeds RANS/Mixing-plane (Lines) and URANS Evaluations (dots) at Cruise-Flight Conditions for Different OGV Geometries

ment in terms of isentropic efficiency. This improvement has been attributed by the suppression of OGV shroud-corner separations as illustrated in FIGURE 14 (which shows axial slices colored by the Mach number downstream of the OGV). Hubcorner separations can also be observed in this same FIGURE 14 (at 7 o'clock) and are not reduced by the new OGV row. This region of low flow momentum has proven to be quite difficult to be removed even though several attempts have been done. In particular, a technique inspired from the work of Gunn et al. [27] has consisted in locally increasing the row solidity by leaning the OGV blades as illustrated in FIGURE 15. This modification referred as "V4", which intended to have the effect of locally increasing the OGV row robustness to blade separation, has not solved the issue as illustrated in FIGURE 16. Nevertheless, performances remain unchanged.

Additional computations have been performed at an increased rotating speed ( $105 \%$ of the nominal rotating speed) in order to verify the fan stage behavior at high power conditions
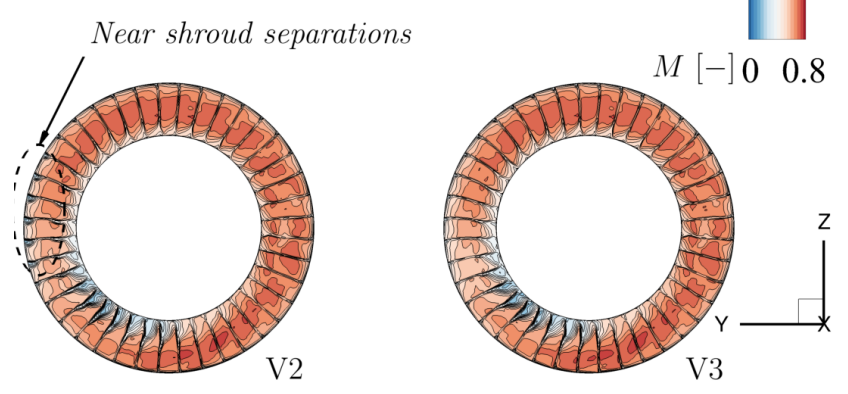

FIGURE 14. Slices Downstream of the OGV Colored with the Mach Number. Comparisons of V2 and V3

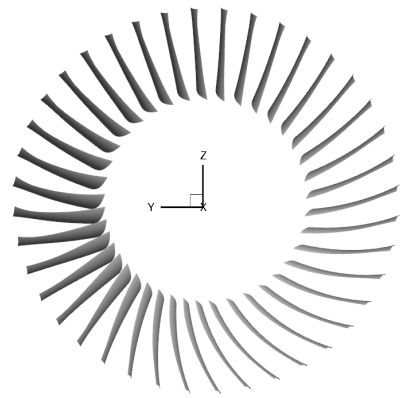

FIGURE 15. OGV modifications in iteration "V4"
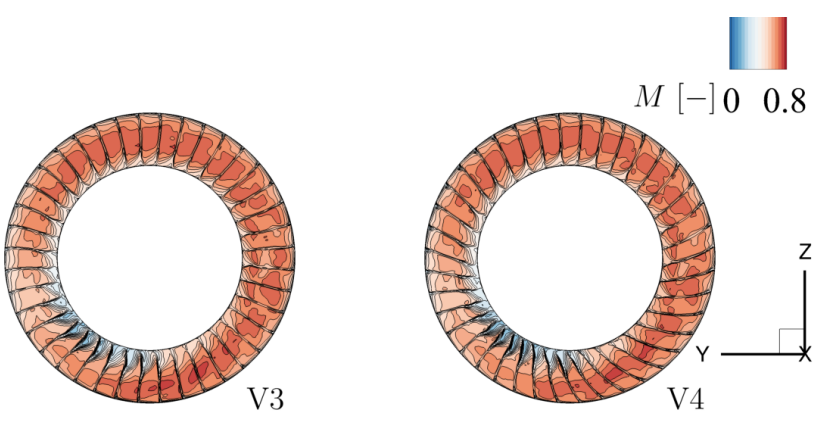

FIGURE 16. Slices Downstream of the OGV Colored by the Mach Number. Comparisons of V3 and V4

(high fan pressure ratio and high masslfow rate) corresponding to top-of-climb thrust levels. The behavior has been deemed correct (cf. Figure 13).

Finally, the resulting design V3 has enabled to recover almost half of the isentropic efficicency lost due to the inlet distortion of the Nautilius configuration. In particular, this process has required very few design iterations. Nevertheless, there is still room for improvement notably by removing the local low mo- 
mentum region near the OGV hub. This could be achieved either by additional fan stage design iterations or by adjusting the rear fuselage shaping in order to reduce the inlet distortion.

The next step of the investigation is the assessment of the new geometry's operability in high-lift conditions.

\section{OPERABILITY ASSESSMENT}

The fan operability assessment has been conducted at takeoff high-lift and high angle of attack conditions $\left(M_{\text {flight }}=0.25\right)$. Hence, an additional aircraft steady state computation has been performed in order to determine the new engine working conditions as well as the new inlet distortion. In these conditions, the reduced value of Mach number and the higher value of massflow rate result in a thinner fuselage boundary layer compared to the one in cruise conditions as highlighted by FIGURE 17 and FIG-

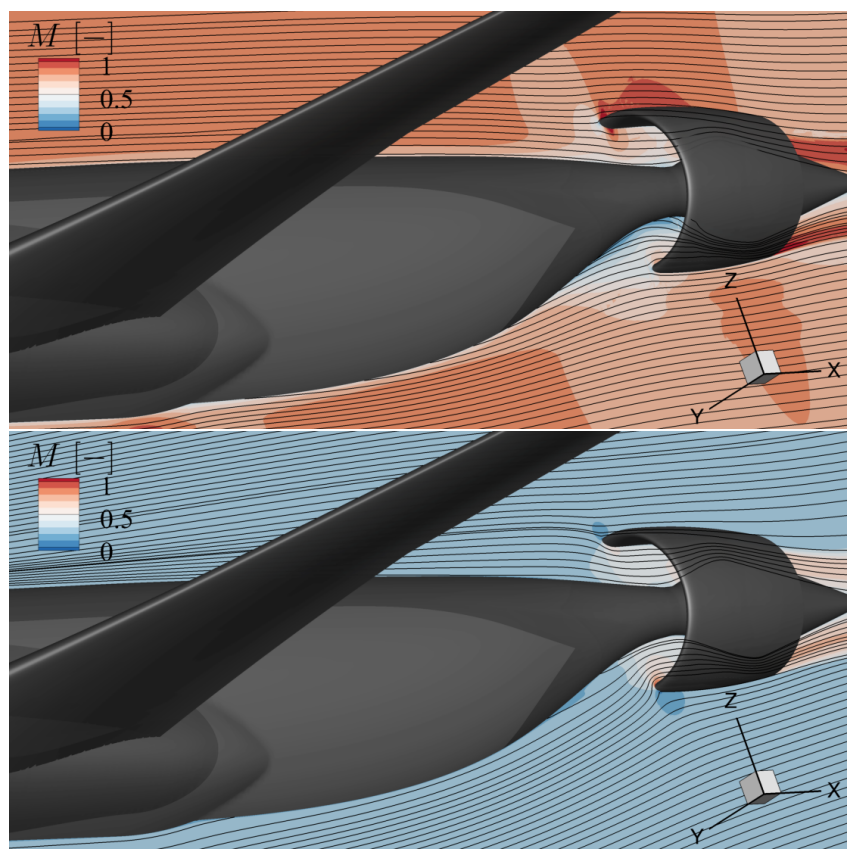

FIGURE 17. Streamlines and Engine $(x O z)$ Plane Colored by the Mach Number of the Nautilius Configuration at Cruise (top picture) and Take-off (down picture) Conditions $\left(M_{\text {flight,cruise }}=0.82\right.$, $M_{\text {flight }, \text { take }- \text { off }}=0.25$ )

URE 18 which respectively show the engine plane $(x O z)$ of the Nautilius configuration colored by the Mach Number at cruise and take-off conditions and a comparison of the stagnation pressure and axial velocity distortions upstream of the fan face for both the Nautilius and the Podded configurations. Compared to cruise conditions, the inflow pattern is less distorted, which is the

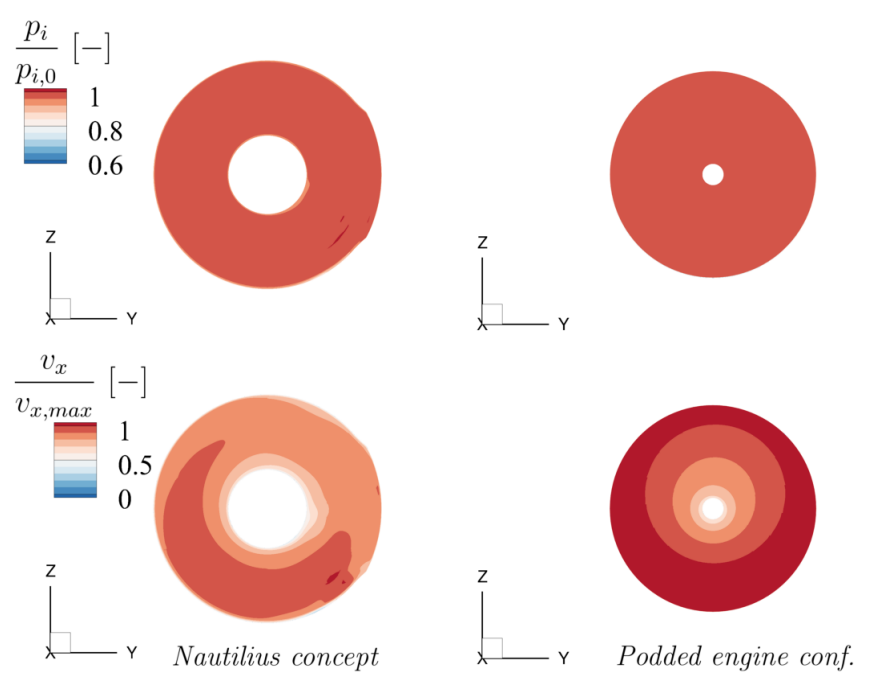

FIGURE 18. Inlet Distortions Colored by Stagnation Pressure Ratio (top) and Normalized Axial Velocity (down) of the Nautilius (left) and the Reference Podded Engine (right) Configurations (Steady RANS Computations with Body-force Source Terms) at Take-Off Conditions

effect of a thinner fuselage boundary layer due to the increase of the massflow rate.

The second step has consisted in assessing the fan stage operating points along the iso-rotating-speed lines by means of URANS computations. This assessment has been performed from the take-off flight conditions up to the occurrence of instabilities for both configurations. The assumption here is that the incoming distortion is not affected by the change of operating condition along the iso-speed, which is admitted by the authors to be questionable and would deserve further validation. FIGURE 19 reports the stagnation and static-to-stagnation pressure ratios characteristics. In this figure, the red and blue lines have been assessed by URANS computations and dots represent working conditions of interest for the throttle margin assessment. It is assumed that instabilities appear when the maximum of staticto-stagnation pressure ratio is reached [38], although authors admit that more recent and more sophisticated stability criteria in distorted conditions can be adopted [29]. Therefore, the stability margin $S M$ definition is evaluated at this static-to-stagnation pressure ratio condition based on the following equation (5) :

$$
S M=\frac{\left(\frac{p_{i} / p_{i, 0}}{\dot{m}_{\text {corr }}}\right)_{\left(p / p_{i, 0}\right)_{\max }}-\left(\frac{p_{i} / p_{i, 0}}{\dot{m}_{\text {corr }}}\right)_{\text {take-off flight condition }}}{\left(\frac{p_{i} / p_{i, 0}}{\dot{m}_{\text {corr }}}\right)_{\text {take-off flight condition }}}
$$

Finally, the estimated stability margin of both configurations (Nautilius and Podded) are respectively $S M_{\text {Naut } ., V 3}=21.7 \%$ and 

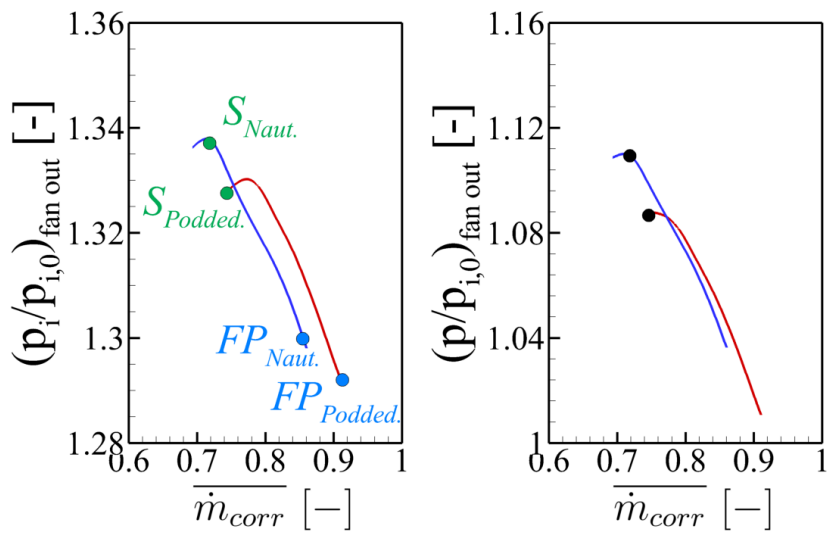

FIGURE 19. Stagnation and Static-to-Stagnation Pressure Ratios Maps (URANS Computations) at Take-off High-lift Conditions for both the Nautilus and the Podded Configurations. S: Stall Condition, FP: Flight Point

$S M_{\text {Podded,ref. }}=25.6 \%$, which implies that the Nautilius configuration associated with the new fan design V3 brings a stability margin reduction of $\Delta S M_{\text {Naut.,V3-podded,ref. }}=-3.9 \%$. This drop can be attributed to both the angle of attack distortion at the air inlet (and notably the flow angle inlet distortion) and the new fan design. Indeed, changes have been done in order to maximize the performances at cruise without verifying the impact on the operability (which could have been done through criteria such as solidity, diffusive factor, etc.). However, the stability margin has been deemed acceptable for a first fan design.

\section{CONCLUSION, DISCUSSION AND PERSPECTIVES}

In this paper, a power savings assessment coupled with a fan design investigation on the Nautilius engine integration concept has been conducted by means of numerical simulations.

Airframe computations have been carried out with the fan stage modeled by body-force source terms and have enabled to estimate a PSC superior to $10 \%$. However, this value has to be considered with caution as the fan performance loss is not taken into account in the power balance breakdown, which remains a strong omission to the extent that the engine faces an important inlet distortion.

In order to provide an assessment of the fan stage performance loss, a fan design activity has been conducted and has demonstrated that half of the initial performance loss can be restored through very few (three) design iterations. These iterations have mainly consisted in adapting the row profiles (fan and OGV) to their respective incoming flow. This has resulted in a fan row adapted to the circumferential averaged inflow, while the OGV has been adapted to the time-averaged inflow, which im- plies a non-axisymmetric OGV. Nevertheless, the isentorpic efficiency loss remains relatively high. Among the identified ways of improvement, reducing the incoming distortion is reckoned to be the most promising solution. Therefore, the authors' feedback on this design activity is that the fan stage design must be strongly coupled with the airframe design.

The operability of the new design has been assessed in takeoff high-lift conditions and has been deemed acceptable. However, this selected flight condition is not necessarily the most critical condition of the flight envelope. Indeed, as the proportion of the ingested fuselage boundary layer flow to the total engine massflow is reduced for high engine massflow rate and low aircraft velocity, the inlet distortion is stronger at cruise than at takeoff. Therefore, an estimation of the fan stability margin should also be made at other flight conditions, notably at top-of-climb higher power conditions.

Finally, in order to go deeper into this concept's feasibility assessment, the next part of this study will be focused on the assessment of the aeroelasticity and aeroacoustics of the fan and OGV blades.

\section{ACKNOWLEDGMENT}

The authors would like to acknowledge Ludovic Wiart for its assistance and for conducting the aircraft computations for this project.

\section{REFERENCES}

[1] ACARE, 2017. "Strategic research \& innovation agenda executive summary". ACARE4europe.org, 1.

[2] Peeters, P., Middel, J., and Hoolhorst, A., 2005. Fuel efficiency of commercial aircraft: an overview of historical and future trends. Tech. rep., NLR.

[3] Plas, A., Sargeant, M., Madani, V., Crichton, D., Greitzer, E., Hynes, T., and Hall, C., 2007. "Performance of a boundary layer ingesting (bli) propulsion system". In 45th American Institute of Aeronautics and Astronautics Aerospace Sciences Meeting and Exhibit, Reno, NV, January, pp. 811.

[4] Hardin, L., Tillman, T., Sharma, O. P., Berton, J., and Arend, D. J., 2012. "Aircraft system study of boundary layer ingesting propulsion". 48th AIAA/ASME/SAE/ASEE Joint Propulsion Conference \& Exhibit, 3993.

[5] Liou, M.-S., and Lee, B. J., 2012. "Minimizing inlet distortion for hybrid wing body aircraft". Journal of Turbomachinery, 134(3), p. 031020.

[6] Defoe, J. J., and Spakovszky, Z. S., 2013. "Effects of boundary-layer ingestion on the aero-acoustics of transonic fan rotors". Journal of Turbomachinery, 135(5), p. 51013.

[7] Florea, R. V., Matalanis, C., Hardin, L. W., Stucky, M., and Shabbir, A., 2015. "Parametric analysis and design for 
embedded engine inlets". Journal of Propulsion and Power, 31(3), May-June.

[8] Liou, M.-F., Kim, H., Lee, B., and Liou, M.-S., 2017. "Aerodynamic design of integrated propulsion-airframe configuration of the hybrid wing-body aircraft". In 35th AIAA Applied Aerodynamics Conference.

[9] Pandya, S. A., Uranga, A., Espitia, A., and Huang, A., 2014. "Computational assessment of the boundary layer ingesting nacelle design of the $\mathrm{d} 8$ aircraft". In 52nd Aerospace Sciences Meeting, p. 0907.

[10] Drela, M., 2009. "Power balance in aerodynamic flows". AIAA journal, 47(7), pp. 1761-1771.

[11] Wiart, L., Atinault, O., Boniface, J.-C., and Barrier, R., 2016. "Aeropropulsive performance analysis of the nova configurations". In 30th Confress of the International Council of the Aerodynamical Sciences.

[12] Jansen, R., Bowman, C., Jankovsky, A., Dyson, R., and Felder, J., 2017. "Overview of nasa electrified aircraft propulsion (eap) research for large subsonic transports". In 53rd AIAA/SAE/ASEE Joint Propulsion Conference, p. 4701.

[13] Negulescu, C., and Airbus-Operation-SAS, 2017. Patent : Assembly for aircraft comprising engines with boundary layer propulsion by injection, fr1655719 (2016) \& us20170361939a1.

[14] Wiart, L., and Negulescu, C., 2018. "Exploration of the aribus "nautilius" engine integration concept". In 31st Congress of the International Council of the Aeronautical Sciences.

[15] Peters, A., 2014. "Ultra-short nacelles for low fan pressure ratio propulsors". $\mathrm{PhD}$ thesis, MIT, February.

[16] Thollet, W., Dufour, G., and Carbonneau, X., 2016. "Assessment of body force methodologies for the analysis of intake-fan aerodynamic interactions". In Proceedings of ASME Turbo Expo 2016, no. GT2016-57014, p. V02CT39A036.

[17] Cao, T., Vadlamani, N. R., Tucker, P. G., Smith, A., Slaby, M., and Sheaf, C. T., 2016. "Fan-intake interactions under high incidence". Journal of Engineering for Gas Turbines and Power, 139(4), p. 041204.

[18] Thollet, W., 2017. "Body-force modeling of fanairframe interactions". $\mathrm{PhD}$ thesis, Institut Supérieur de l'Aéronautique et de l'Espace.

[19] Carnevale, M., Wang, F., and Di Mare, L., 2018. "Calculation of intake-fan-bypass interaction with a fan similarity model". In ASME Turbo Expo 2018: Turbomachinery Technical Conference and Exposition, no. GT2018-75115, p. V02CT42A003.

[20] Godard, B., De Jaeghere, E., Nasr, N. B., Marty, J., Barrier, R., and Gourdain, N., 2017. "Methodologies for turbofan inlet aerodynamics prediction". In 35th AIAA Applied Aerodynamics Conference, p. 3413.
[21] Gunn, E. J., Tooze, S. E., Hall, C. A., and Colin, Y., 2013. "An experimental study of loss sources in a fan operating with continuous inlet stagnation pressure distortion". Journal of Turbomachinery, 135(5), p. 051002.

[22] Hall, D. K., Huang, A. C., Uranga, A., Greitzer, E. M., Drela, M., and Sato, S., 2017. "Boundary layer ingestion propulsion benefit for transport aircraft". Journal of Propulsion and Power, 33(5), pp. 1118-1129.

[23] Provenza, A. J., Duffy, K. P., and Bakhle, M. A., 2019. "Aeromechanical response of a distortion-tolerant boundary layer ingesting fan". Journal of Engineering for Gas Turbines and Power, 141(1), p. 011011.

[24] Hall, D. K., 2015. "Analysis of civil aircraft propulsors with boundary layer ingestion.". PhD thesis, Massachusetts Institute of Technology. Department of Aeronautics and Astronautics.

[25] Godard, B., De Jaeghere, E., and Gourdain, N., 2019. "Efficient design investigation of a turbofan in distorted inlet conditions". In Proceedings of ASME Turbo Expo 2019: Turbomachinery Technical Conference and Exposition, no. GT2019-90471.

[26] Hall, D., Greitzer, E., and Tan, C., 2017. "Analysis of fan stage conceptual design attributes for boundary layer ingestion". Journal of Turbomachinery, 139(7), p. 071012.

[27] Gunn, E., and Hall, C., 2017. "Non-axisymmetric stator design for boundary layer ingesting fans". In Proceedings of ASME Turbo Expo 2017: Turbomachinery Technical Conference and Exposition, Vol. GT2017-63082, p. V001T01A003.

[28] Page, J. H., Hield, P., and Tucker, P. G., 2018. "Effect of inlet distortion features on transonic fan rotor stall". Journal of Turbomachinery, 140(7), p. 071008.

[29] Perovic, D., Hall, C. A., and Gunn, E., 2019. "Stall inception in a boundary layer ingesting fan". Journal of Turbomachinery, 141(9), p. 091007.

[30] Cambier, L., Heib, S., and Plot, S., 2013. "The onera elsa cfd software: input from research and feedback from industry". Mechanics \& Industry, 14(3), pp. 159-174.

[31] Thollet, W., Dufour, G., Carbonneau, X., and Blanc, F., 2016. "Body-force modeling for aerodynamic analysis of air intake-fan interactions". International Journal of $\mathrm{Nu}$ merical Methods for Heat \& Fluid Flow, 26(7), pp. 20482065.

[32] Jameson, A., Schmidt, W., Turkel, E., et al., 1981. "Numerical solutions of the euler equations by finite volume methods using runge-kutta time-stepping schemes". AIAA paper, 1259, p. 1981.

[33] Spalart, P. R., and Allmaras, S. R., 1992. "A one equation turbulence model for aerodinamic flows.". AIAA journal, 94.

[34] Roe, P. L., 1981. "Approximate riemann solvers, parameter vectors, and difference schemes". Journal of computational 
physics, 43(2), pp. 357-372.

[35] Smith, B., 1990. "The k-kl turbulence model and wall layer model for compressible flows". In AIAA, Fluid Dynamics, Plasma Dynamics and Lasers Conference, 21 st, Seattle, WA, p. 1990.

[36] NUMECA, 2008. "User manualautogrid5 release 8.4 : A full automatic hexahedral grid generator for all types of rotating macmanual".

[37] Arntz, A., 2014. "Civil aircraft aero-thermo-propulsive performance assessment by an exergy analysis of high-fidelity cfd-rans flow solutions". PhD thesis, Université de Lille 1.

[38] Dunham, J., 1965. "Non-axisymmetric flows in axial compressors". Mechanical Engineering Science Monograph, MESM. 